\title{
Crescimento e qualidade de mudas de Handroanthus heptaphyllus em substrato com esterco bovino
}

\author{
Alysson Canabrava Lisboa ${ }^{1}$ (D), Cícero José Azevedo Homem de Melo Júnior ${ }^{2}$ (D), Fernanda Paula Alves Tavares ${ }^{1}$, \\ Rodrigo Braga de Almeida ${ }^{(\mathbb{D}}$, Lucas Amaral de Melo ${ }^{4}$ (D), Iris Cristiane Magistrali ${ }^{1 *}$ (iD \\ ${ }_{1}^{1}$ Universidade Federal Rural do Rio de Janeiro, BR 465, Km 7, CEP 23890-000, Seropédica, RJ, Brasil \\ ${ }^{2}$ Empresa VP Ecologia Empresarial LTDA, Rua Antônio Valente da Silva, 54, Chácara Oralia, CEP 12080-230, Taubaté, SP, Brasil \\ ${ }^{3}$ Fibria, Rod. MS 395, Km 20, Zona Rural, CP. 529, CEP 79601-970, Três Lagoas, MS, Brasil \\ ${ }^{4}$ Universidade Federal de Lavras, CP. 3037, CEP 37200-000, Lavras, MG, Brasil
}

\author{
"Autor correspondente: \\ irismagistrali@gmail.com \\ Termos para indexação: \\ Adubação orgânica \\ Propagação vegetal \\ Ipê roxo \\ Index terms: \\ Organic nutrition \\ Plant propagation \\ Purple ipe \\ Histórico do artigo: \\ Recebido em 10/08/17 \\ Aprovado em 14/12/17 \\ Publicado em 09/07/18 \\ doi: 10.4336/2018.pfb.e201701485
}

\begin{abstract}
Resumo - Objetivou-se verificar a influência do uso de proporções de esterco bovino na composição do substrato sobre o crescimento e a qualidade das mudas de Handroanthus heptaphyllus. Utilizou-se um experimento em delineamento inteiramente casualizado. Foram avaliadas cinco diferentes proporções de esterco bovino na composição do substrato: $0,15,30,45$ e $60 \%$.Verificou-se que as mudas de $H$. heptaphyllus responderam positivamente à utilização de $21 \%$ a $28 \%$ esterco bovino.
\end{abstract}

\section{Growth and seedlings quality of Handroanthus heptaphyllus with cattle manure in the substrate composition}

\begin{abstract}
The objective of this work was to verify the influence of different proportions of bovine manure on substrate composition for Handroanthus heptaphyllus growth and seedlings quality. Five different ratios of bovine manure in the substrate composition were evaluatedin the following proportions: $0,15,30,45$ and $60 \%$. We verified that $H$. heptaphyllus seedlings responded positively to bovine manure inproportions of $21 \%$ to $28 \%$.
\end{abstract}

Handroanthus heptaphyllus (Vell.) Mattos, popularmente conhecido como ipê roxo, apresenta grande importância ecológica. Trata-se de uma espécie com ampla distribuição no território brasileiro, usada frequentemente para fins paisagísticos (Lorenzi, 2008). Sua madeira apresenta alta densidade, com grande resistência e maleabilidade, sendo empregada na construção civil (Borges et al., 2014).

Dentre os fatores que afetam a produção de mudas florestais, como é o caso de H. heptaphyllus, pode-se destacar o tipo de substrato a ser usado. No Brasil, o esterco animal misturado ao solo tem sido usado na composição de substratos para produção de mudas de café (Dias et al., 2009), de plantas hortícolas (Abreu et al., 2010) e, recentemente, como substrato para a produção de mudas florestais (Caldeira et al., 2008; Melo et al., 2014; Faria et al., 2017). O esterco animal, quando utilizado de maneira correta, pode proporcionar melhoria nos atributos físico-químicos do substrato, além de estimular a atividade microbiana (Artur et al., 2007).

Em função do crescente aumento na demanda por mudas de espécies nativas e devido à importância de $H$. 
heptaphyllus em programas de restauração ambiental, são necessários estudos a respeito da produção de mudas desta espécie. Desta forma, objetivou-se neste trabalho verificar a influência do esterco bovino na composição do substrato sobre o crescimento e a qualidade de mudas de H. heptaphyllus.

$\mathrm{O}$ estudo foi conduzido em área a pleno sol no Viveiro Florestal da empresa Acácia Amarela Produção de Mudas e Consultoria Ambiental Ltda., com sede na BR- 465 km 51, Município de Seropédica, RJ. O clima da região, de acordo com a classificação de Köppen, é do tipo Aw (chuvas no verão).

Foram avaliados cinco tratamentos com diferentes proporções de esterco bovino na composição do substrato. O esterco foi curtido durante um mês a pleno sol. Além do esterco bovino, os substratos continham areia lavada na proporção volumétrica constante de $20 \%$ e subsolo argiloso nas proporções volumétricas necessárias para completar os $100 \%$. Na Tabela 1 apresenta-se a composição dos substratos usados como tratamentos para produção de mudas de H. heptaphyllus.

Tabela 1. Tratamentos usados como formulação dos substratos para produção de mudas de Handroanthus heptaphyllus.

\begin{tabular}{cccc}
\hline Tratamento & $\begin{array}{c}\text { Esterco } \\
(\mathbf{\%})\end{array}$ & $\begin{array}{c}\text { Areia } \\
(\mathbf{\%})\end{array}$ & $\begin{array}{c}\text { Subsolo Argiloso } \\
\text { (\%) }\end{array}$ \\
\hline $\mathrm{T}_{0}$ & 0 & 20 & 80 \\
$\mathrm{~T}_{15}$ & 15 & 20 & 65 \\
$\mathrm{~T}_{30}$ & 30 & 20 & 50 \\
$\mathrm{~T}_{45}$ & 45 & 20 & 35 \\
$\mathrm{~T}_{60}$ & 60 & 20 & 20 \\
\hline
\end{tabular}

Depois de preparados e homogeneizados os substratos, retirou-se uma amostra de cada tratamento para análise química. Em seguida, foram preenchidos os sacos plásticos, com dimensões de $14 \mathrm{~cm}$ x $20 \mathrm{~cm}$. Foram semeadas quatro sementes por recipiente diretamente a pleno sol. Após a germinação, constatada pela emergência das plântulas, realizou-se o desbaste deixando-se apenas uma plântula por recipiente. Durante toda a condução dos experimentos, fez-se irrigação duas vezes ao dia para se manter a umidade dos substratos com as mudas à "capacidade de campo". O experimento foi instalado em delineamento inteiramente casualizado, formado pelos cinco tratamentos, em cinco repetições, e 18 plantas por parcela.

Aos 120 dias após a semeadura, foram realizadas avaliações de altura da parte aérea (régua graduada, em $\mathrm{cm}$ ), diâmetro do coleto (paquímetro digital, em $\mathrm{mm}$ ) e matéria seca, as mudas foram cortadas na altura do coleto e, posteriormente, separadas em parte aérea e sistema radicular. A matéria seca da parte aérea foi colocada diretamente em sacos de papel, enquanto que para a obtenção da matéria seca do sistema radicular, primeiramente o torrão foi lavado em água corrente para a retirada do substrato residual. Os sacos de papel foram devidamente identificados e levados à estufa com circulação de ar forçada à temperatura de $65^{\circ} \mathrm{C}$, até atingirem peso constante.

Com base nas características morfológicas avaliadas, foram calculadas as relações entre a altura da parte aérea e o diâmetro de coleto (H/DC), a matéria seca da parte aérea e a matéria seca do sistema radicular (MSPA/MSR) e também o índice de qualidade de Dickson (IQD). O Índice de Qualidade de Dickson (IQD) reflete em um único valor o equilíbrio da distribuição de todos os parâmetros analisados isoladamente. Quanto maior o valor do IQD, melhor a qualidade das mudas.

Os valores observados e as suas relações foram submetidos à análise de variância, a 5\% de probabilidade de erro. Quando detectadas diferenças significativas, os dados foram submetidos à análise de regressão, por meio do software SISVAR (Ferreira, 2011).

Pelos resultados das análises químicas (Tabela 2) referentes aos tratamentos utilizados para a produção de mudas de H. heptaphyllus, é possível verificar que à medida que se elevou a proporção do esterco bovino na composição do substrato (Tabela 1), houve aumento no $\mathrm{pH}$, aumento da concentração de todos os nutrientes e redução de $\mathrm{H}+\mathrm{Al}$. De maneira geral, o uso do esterco proporcionou melhoria nas características químicas dos substratos.

Considerando o $\mathrm{pH}$ dos substratos testados (Tabela 2), apenas $T_{0}$ (sem adição de esterco) está fora do intervalo dito como adequado para a produção de mudas de espécies florestais, que é de 5,5 a 6,5 (Gonçalves \& Poggiani, 1996), o que é ratificado pelo baixo valor de saturação por bases e alto de saturação por alumínio. Já para o fósforo, todos os substratos necessitariam de adubação complementar, via adubação de base e ou adubação de cobertura, conforme descritas por Davide et al. (2012). Porém, com o acréscimo de esterco ao substrato, estes valores se aproximam dos valores considerados adequados (de 400 a $800 \mathrm{mg} \mathrm{dm}^{-3}$ ), conforme indicado por Gonçalves \& Poggiani (1996). 
Tabela 2. Resultados da análise química dos substratos utilizados para produção de mudas de Handroanthus heptaphyllus.

\begin{tabular}{|c|c|c|c|c|c|c|c|c|c|c|}
\hline \multirow{2}{*}{ Trat. } & \multirow{2}{*}{$\mathrm{pH}$} & $\mathrm{Ca}$ & $\mathrm{Mg}$ & K & $\mathrm{H}+\mathrm{Al}$ & $\mathrm{Al}$ & $\mathrm{T}$ & $\mathrm{V}$ & $\mathrm{m}$ & \multirow{2}{*}{$\frac{\mathrm{P}}{\mathrm{mg} \mathrm{dm}-3}$} \\
\hline & & \multicolumn{6}{|c|}{ - } & \multicolumn{2}{|c|}{------ \% ------ } & \\
\hline $\mathrm{T}_{0}$ & 5,4 & 1,00 & 0,40 & 0,03 & 2,10 & 0,60 & 3,55 & 41 & 29,23 & 4 \\
\hline $\mathrm{T}_{15}$ & 5,7 & 2,30 & 0,50 & 1,44 & 1,30 & 0,20 & 5,76 & 77 & 4,29 & 45 \\
\hline $\mathrm{T}_{30}$ & 6,0 & 3,30 & 0,70 & 2,88 & 1,30 & 0,00 & 8,61 & 85 & 0,00 & 100 \\
\hline $\mathrm{T}_{45}$ & 6,2 & 3,00 & 1,80 & 5,14 & 1,00 & 0,00 & 11,70 & 91 & 0,00 & 157 \\
\hline $\mathrm{T}_{60}$ & 6,5 & 3,70 & 2,00 & 7,00 & 1,00 & 0,00 & 14,90 & 93 & 0,00 & 241 \\
\hline
\end{tabular}

Em que: Trat. = tratamento; $\mathrm{pH}=$ potencial hidrogeniônico; $\mathrm{H}+\mathrm{Al}=$ acidez potencial; $\mathrm{T}$ = capacidade de cátions efetiva; $\mathrm{V}=$ saturações de bases; $\mathrm{m}=$ saturação por alumínio; $\mathrm{T}_{0}, \mathrm{~T}_{15}, \mathrm{~T}_{30}, \mathrm{~T}_{45}$ e $\mathrm{T}_{60}=0 \%, 15 \%, 30 \%, 45 \%$ e $60 \%$ de esterco bovino, respectivamente, na composição do substrato.

Ainda em relação às características químicas, podese considerar que o substrato sem adição de esterco $\left(\mathrm{T}_{0}\right)$ apresenta baixos teores dos macronutrientes $\mathrm{Ca}$, $\mathrm{Mg}$ e $\mathrm{K}$, enquanto os substratos com $45 \%\left(\mathrm{~T}_{45}\right)$ e $60 \%\left(\mathrm{~T}_{60}\right)$ de esterco apresentam valores acima dos adequados, conforme recomendação de Gonçalves \& Poggiani (1996). Desta forma, com base nestes três macronutrientes, os tratamentos $\mathrm{T}_{15}$ e $\mathrm{T}_{30}$ seriam os mais interessantes para serem utilizados.

Foram verificadas diferenças significativas para todas as características morfológicas avaliadas (Tabela 3). A altura das mudas de $H$. heptaphyllus atingiu seu ponto de máximo $(18 \mathrm{~cm})$ com $28 \%$ de esterco na composição do substrato, tendência também observada para o diâmetro do coleto (DC), com valores máximos estimados na proporção de $26 \%$ de esterco bovino (Figura 1). Segundo Landis et al. (2010) e Scheer et al. (2012), o diâmetro do coleto está diretamente relacionado com a sobrevivência das mudas em campo, enquanto Thompson (1985) afirma que o crescimento inicial também depende da altura inicial das mudas. Portanto, as mudas produzidas com $26 \%$ a $28 \%$ de esterco no substrato, que apresentaram os maiores valores para essas duas variáveis, provavelmente estariam mais aptas a sobreviverem e crescerem em campo após o plantio.

Tabela 3. Resultados da análise de variância das características morfológicas de mudas de Handroanthus heptaphyllus, aos 120 dias após a semeadura.

\begin{tabular}{|c|c|c|c|c|c|c|c|c|c|}
\hline \multirow{2}{*}{ FV } & \multirow{2}{*}{ GL } & \multicolumn{8}{|c|}{ Quadrados médios } \\
\hline & & $\mathbf{H}$ & DC & H/DC & MSPA & MSR & MST & MSPA/MSR & IQD \\
\hline Tratamento & 4 & $105,26^{*}$ & $4,38 *$ & $0,86^{*}$ & $19,00^{*}$ & $2,40^{*}$ & $34,32 *$ & $5,90^{*}$ & $0,81^{*}$ \\
\hline Erro & 20 & 1,51 & 0,07 & 0,03 & 0,33 & 0,10 & 0,73 & 1,47 & 0,03 \\
\hline CV (\%) & - & 8,91 & 6,25 & 6,15 & 21,11 & 32,55 & 23,15 & 37,40 & 29,04 \\
\hline Média Geral & - & 13,77 & 4,27 & 3,16 & 2,74 & 0,96 & 3,70 & 3,25 & 0,59 \\
\hline DesvPad & - & 1,27 & 0,27 & 0,19 & 0,58 & 0,31 & 0,86 & 1,22 & 0,17 \\
\hline
\end{tabular}

Em que: $n s$ = Não significativo; * = Significativo a 5\% de probabilidade de erro, pelo teste F. CV: coeficiente de variação; DesvPad: desvio padrão; H: altura da parte aérea; DC: diâmetro do coleto; H/DC: relação altura da parte aérea e diâmetro do coleto; MSPA: matéria seca da parte aérea; MSR: matéria seca de raízes; MST: matéria seca total; MSPA/MSR: relação matéria seca da parte aérea e matéria seca de raízes; IQD: índice de qualidade de Dickson.

Para matéria seca total da parte aérea e das raízes, também se verificou que a proporção de esterco influenciou significativamente nos valores obtidos aos 120 dias após a semeadura (Figura 2). Pela estimativa dos valores máximos da matéria seca obtidos pelas regressões, observa-se um ponto máximo em torno de $26 \%$ de esterco bovino na composição do substrato.
Segundo Davide et al. (2012), a produção de matéria seca pelas mudas tem sido considerada um importante parâmetro para se analisar a qualidade das mudas, pois reflete o quanto ela cresça. Quanto mais MSPA, maior taxa fotossintética da planta. Porém, se as raízes não se desenvolvem o suficiente, poderá ocorrer problemas com estresse hídrico e na capacidade de absorção dos nutrientes, principalmente em condições de campo. 


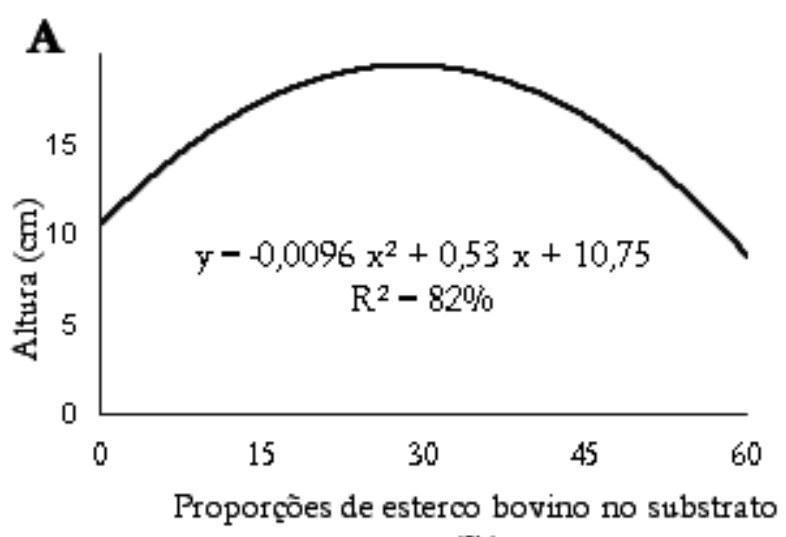

$(\%)$

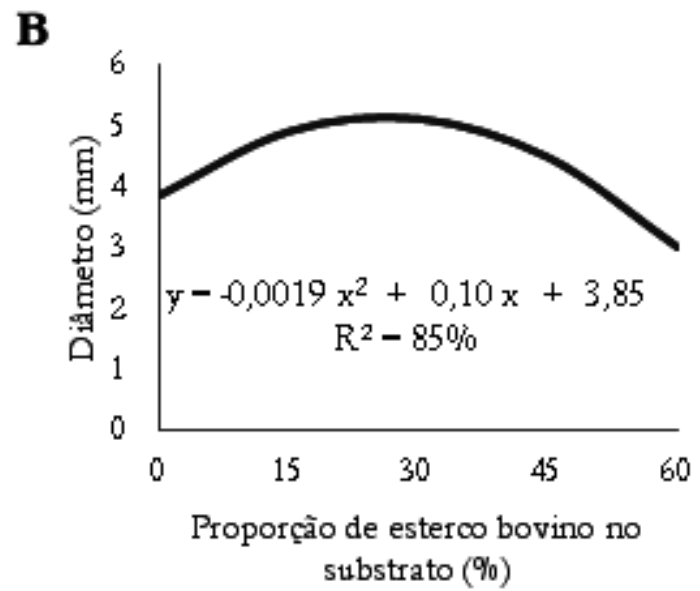

Figura 1. Altura (A) e diâmetro do coleto (B) de mudas de Handroanthus heptaphyllus, aos 120 dias após a semeadura, em função da proporção de esterco bovino na composição dos substratos.

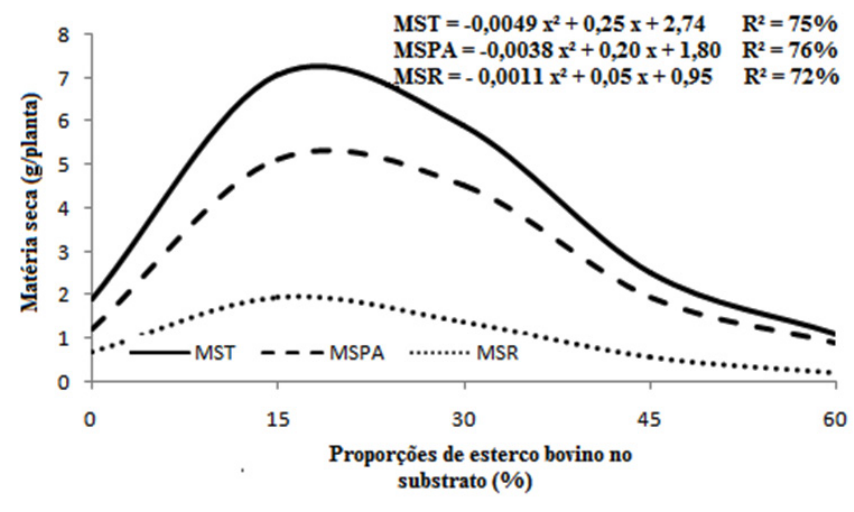

Figura 2. Matéria seca total (MST), matéria seca da parte aérea (MSPA) e matéria seca de raízes (MSR) de mudas de Handroanthus heptaphyllus, aos 120 dias após a semeadura, em função da proporção de esterco bovino na composição dos substratos.

Os resultados encontrados para o acúmulo de matéria seca nas plantas coincidem com a recomendação feita anteriormente a respeito das características químicas dos substratos, sendo as proporções de esterco entre $15 \%$ $\left(\mathrm{T}_{15}\right)$ e $30 \%\left(\mathrm{~T}_{30}\right)$, as mais recomendadas. Paiva Sobrinho et al. (2010), ao avaliarem mudas de Hancornia speciosa, Dipteryx alata e Eugenia dysenterica bservaram que o acréscimo de esterco bovino no solo acarretarou aumento do $\mathrm{pH}$ e de matéria orgânica, reduzinando a massa seca produzida pelas plantas. A análise do índice de qualidade de Dickson (IQD) indicou que cerca de $23 \%$ de esterco bovino na composição do substrato seria o ideal, sendo obtidas mudas com maior qualidade (Figura 3).

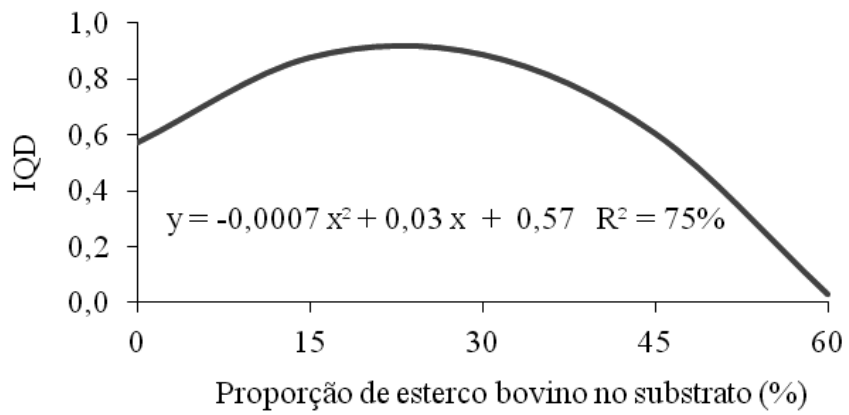

Figura 3. Índice de qualidade de Dickson (IQD) em mudas de Handroanthus heptaphyllus, aos 120 dias após a semeadura, em função da proporção de esterco bovino na composição dos substratos.

Para a formulação de um substrato com materiais alternativos, como é o caso do esterco, é necessário que o componente seja de fácil obtenção, tenha um uso ambientalmente correto, tenha estrutura estável, seja de baixo custo, assim como deve propiciar ao substrato boas características físicas e químicas (Klein, 2015). A perda de qualidade das mudas com a adição ds mais de $28 \%$ de esterco ao substrato pode ser explicada pelo desequilíbrio da porosidade total, com o predomínio da microporosidade em relação à macroporosidade, conforme relatado por Caldeira et al. (2008) e Abreu et al. (2017). .

Segundo Caldeira et al. (2008), a matéria orgânica tem como finalidade aumentar a retenção de água e nutrientes para as mudas. Por esse motivo, o esterco bovino é 
amplamente utilizado como fonte de matéria orgânica em substratos para produção de mudas florestais. No entanto, os mesmos autores, além de Faria et al. (2017), ressaltam que em substrato composto por grandes proporções de composto orgânico, seja ele esterco bovino ou outros componentes, as mudas tendem a apresentar menor crescimento, possivelmente devido ao predomínio de microporosidade no substrato, diminuindo a aeração, e prejudicando o desenvolvimento radicular das mudas.

Zanatta et al. (2016), utilizando diferentes combinações de substrato na produção de mudas de ipê roxo, relataravam maior crescimento em altura das plantas com a adição de compostos orgânicos. No entanto, diferentes composições de substrato podem acarretar diferentes respostas de crescimento. Caetano (2016), verificou maior altura média de mudas de H. heptaphyllus produzidas em substratos à base de composto de lixo e composto de poda de árvores, em relação às mudas produzidas com substrato comercial à base de casca de pinus.

Ao avaliar parâmetros como altura, diâmetro do coleto, número de folhas, área foliar e matéria seca de mudas de Calophyllum brasiliense, Artur et al. (2007) registraram uma diminuição desses parâmetros inversamente proporcional à adição de esterco bovino ao substrato. Da mesma forma, Silva et al. (2013) registraram menor crescimento em mudas de Ormosia arborea após a adição de esterco bovino ao substrato, assim como Melo et al. (2014) para a produção de mudas de Eremanthus erythropappus. No entanto, estes mesmos autores, verificaram melhoria na qualidade de mudas de Eucalyptus grandis com o acréscimo do percentual de esterco ao substrato.

Estudos sobre a composição de substratos adequados para a produção de mudas de espécies florestais nativas ainda são escassos, porém muito importantes, pois cada espécie pode responder de forma distinta. Desta forma, pesquisas como esta são fundamentais para compreender as melhores condições para o crescimento e qualidade das espécies florestais nativas, assim como balizar a escolha dos componentes e suas respectivas proporções na composição do substrato.

\section{Conclusões}

De maneira geral, o uso do esterco bovino, na proporção de $21 \%$ a $28 \%$, proporcionou melhoria nas características químicas dos substratos, contribuindo tanto para o aumento no crescimento, quanto para a qualidade das mudas de Handroanthus heptaphyllus.

O esterco bovino pode ser uma alternativa viável, pois além de apresentar baixo custo, pode ser preparado a partir de material disponível nas propriedades rurais. No entanto, deve-se tomar cuidado, pois quando utilizado em grandes proporções, pode trazer mais prejuízos do que benefícios à produção das mudas.

\section{Referências}

Abreu, A. H. M. et al. Caracterização e potencial de substratos formulados com biossólido na produção de mudas de Schinus terebinthifolius Raddi. e Handroanthus heptaphyllus (Vell.) Mattos. Ciência Florestal, v. 27, n. 4, p. 1179-1190, 2017. DOI: 10.5902/1980509830300.

Abreu, I. M. O. et al. Qualidade microbiológica e produtividade de alface sob adubação química e orgânica. Ciência e Tecnologia de Alimentos, v. 30, p. 108-118, 2010. DOI: 10.1590/S01012061201000050001

Artur, A. G. et al. Esterco bovino e calagem para formação de mudas de guanandi. Pesquisa Agropecuária Brasileira, v. 42, n. 6, p. 843850, 2007. DOI: 10.1590/S0100-204X2007000600011.

Borges, V. P. et al. Emergência e crescimento inicial de Tabebuia heptaphylla (Vell.) Toledo em ambientes contrastantes de luz. Revista Árvore, v. 38, p. 523-531, 2014. DOI: 10.1590/S010067622014000300015.

Caetano, M. C. T. Substratos orgânicos para a produção de mudas de Tabebuia heptaphylla irrigadas com água potável e residuária. 2016. 60 f. Tese (Doutorado em Agronomia) - Universidade Estadual Paulista, Jaboticabal.

Caldeira, M. V. W. et al. Composto orgânico na produção de mudas de aroeira-vermelha. Scientia Agraria, v. 9, n. 1, p. 27-33, 2008.

Davide, A. C. et al. Produção de mudas de candeia. In: Scolforo, J. R. S. et al. (Org.). O manejo sustentável da candeia: o caminhar de uma nova experiência florestal em Minas Gerais. Lavras: UFLA, 2012. p. 43-12.

Dias, R. et al. Fontes e proporção de material orgânico para a produção de mudas em cafeeiro em tubetes. Ciência e Agrotecnologia, v. 33, n. 3, p. 758-764, 2009.

Gonçalves, J. L. M. \& Poggiani, F. Substratos para produção de mudas florestais. In: CONCRESSO LATINO AMERICANO DE CIÊNCIA DO SOLO, 13., 1996, Águas de Lindóia. Anais... Águas de Lindóia: USP-ESALQ/SBCS/ CEA/SLACS/SBM, 1996. CD-ROM.

Klein, C. Utilização de substratos alternativos para produção de mudas. Revista Brasileira de Energias Renováveis, v. 4, p. 4363, 2015.

Lorenzi, H. Árvores brasileiras: manual de identificação e cultivo de plantas arbóreas do Brasil. 5. ed. Nova Odesa, SP: Instituto Plantarum, 2008. v. 1. 368 p. 
Melo, L. A. et al. Crescimento de mudas de Eucalyptus grandis e Eremanthus erythropappus sob diferentes formulações de substrato. Floresta e Ambiente, v. 21, n. 2, p. 234-242, 2014. DOI: 10.4322/ floram.2014.028.

Paiva Sobrinho, S. P. et al. Substratos na produção de mudas de três espécies arbóreas do Cerrado. Revista Brasileira de Ciências Agrárias, v. 5, n. 2, p. 238-243, 2010. DOI: 10.5039/agraria. v5i2a741.

Scheer, M. B. et al. Composto de lodo de esgoto para produção de mudas de Anadenanthera colubrina (Vell.) Brenan. Revista Cerne, v. 18, n. 4, p. 613-621, 2012. DOI: 10.1590/S010477602012000400011 .
Silva, A. L. et al. Influência de diferentes substratos no crescimento inicial de Ormosia arborea (Vell.) Harms (Fabaceae). Revista Verde de Agroecologia e Desenvolvimento Sustentável, v. 8, n. 4, p. 22-27, 2013.

Thompson, B. E. Seedling morphological evaluation-what you can tell by looking. In: Duryea, M. L. Evaluating seedling quality: principles, procedures, and predictive abilities of major tests. Corvallis: Oregon State University, Forest Research Laboratory, 1985. p. $59-85$

Zanatta, T. P. et al. Análise do desenvolvimento inicial de mudas de Tabebuia impetiginosa submetidas a diferentes tipos de substratos. Revista do Instituto Florestal, v. 28, n. 2, p. 103-109, 2016. DOI: $10.24278 / 2178-5031.201628202$. 